\begin{tabular}{|c|c|c|}
\hline $1 \mathrm{r}$ & $\begin{array}{c}\text { European Association for the } \\
\text { Development of Renewable Energies, Environment } \\
\text { and Power Quality (EA4EPQ) }\end{array}$ & $\begin{array}{c}\text { International Conference on Renewable Energies and Power Quality } \\
\text { (ICREPQ'12) } \\
\text { Santiago de Compostela (Spain), 28th to 30th March, } 2012\end{array}$ \\
\hline
\end{tabular}

\title{
Using Renewable Energy Sources in the Province of Manitoba
}

\author{
T. Molinski ${ }^{1}$, T. Yebra ${ }^{2}$, and A. M. Gole ${ }^{2}$ \\ ${ }^{1}$ Section Head Emerging Energy Systems \\ Manitoba Hydro 360 Portage Ave. (18) \\ R3C 0G8, Winnipeg, MB, Canada \\ Phone/Fax number:+001 204 3603472, e-mail: tsmolinski@hydro.mb.ca \\ ${ }^{2}$ Department of Electrical Engineering \\ Engineering Information and Technology Complex \\ University of Manitoba. \\ R3T 2N2, Winnipeg (Canada)
}

Phone/Fax number:+001 204 4749524, e-mail: umyebrav@cc.umanitoba.ca, gole@ee.umanitoba.ca

\begin{abstract}
This paper explores the potential for additional renewable energy options in the Canadian province of Manitoba, which already produces nearly $100 \%$ of its electrical energy using hydro power. It considers the perspectives of the national and provincial governments with regard to the future of electric transportation. It also consolidates available data collected in the province. Finally, it explores the possibilities of future applications of the concept of smart grid in the context of how this may assist the optimal energy source mix for this province.

There are reasons other than economics which could drive Manitobans to invest in renewable energy sources different from hydro power. The electric vehicle $(\mathrm{EV})$ is a prime example of a load that should be supplied by new renewable energy. The reduction in the consumption of petrol, the reduction of pollution, and the education in energy efficiency justify the use of renewable energies in EVs.
\end{abstract}

\section{Key words}

Renewable energies, Electric vehicles, Smart grids.

\section{Introduction}

The use of renewable energy sources such as the wind and sun to produce electricity has been well justified in many locations due to subsidies or policies like renewable portfolio standards, but there are cases in which the arguments are weak. Such is the case of the Canadian province of Manitoba. What makes this case special is the abundance of hydro power in Manitoba (nearly 100\% of electric production). There are three points that support continued investing in hydro power in Manitoba.

1) Using dams to produce electricity is considered a very low emitting natural renewable energy because the process generates very little greenhouse gases.

2) There is a huge untapped potential for more hydro power.
3) The third point is that the price of electricity in Manitoba is the lowest in Canada because the current production of hydro energy exceeds the demands of the population, thus allowing a significant part to be exported to other provinces or the US at a profit.

Thus it is likely that the introduction of other renewable technologies could increase the price of the electricity that Manitobans pay due to the higher cost associated with these technologies. Therefore, if the electricity in Manitoba covers the necessities of the province with the best price, and with very low greenhouse gases, why would Manitobans need to invest in wind mills or solar panels?

Manitobans are spending a lot money in fossil fuels even thought they already have an excess of clean electricity. One of the culprits for the high use of fossil fuels is transportation, and a viable alternative is to move from gasoline to electricity in this sector. Furthermore, changing from fossil fuels to electricity in transportation would have several benefits such as lower greenhouse gases, lower pollution and lower cost of vehicle propulsion energy in the province. Manitoba can take advantage of the present block heater infrastructure, that most Manitobans use to plug in their cars in extreme cold weather $\left(<-20^{\circ} \mathrm{C}\right)$ because conventional cars have to have their engines pre-warmed and we can use this infrastructure to supply charging of EVs. As a result the adaptation of this existing infrastructure in Manitoba would be a less expensive way to charge EVs than in cities from other parts of the world that do not have such an existing infrastructure.

\section{Current situation and natural energy sources in Manitoba}

The province of Manitoba is rich in natural resources. 
Some of them have been exploited successfully to produce electricity, and hydro power has so far met the demand of the population. In the future, other renewable energy sources may be economic for Manitobans. This section will describe the state of the three main natural sources in the province of Manitoba, their present utilization and their potential to generate electricity for future new needs.

\section{A. Predominant position of hydro energy}

The first and most important resource in the province is hydro power. Manitoba has sufficient production of hydro-electricity for its population and economic activities with 5,000 MW of hydro power installed. The hydro generators cover $98 \%$ of the production of electricity [1] (Figure 1). In addition, the hydro sources are not utilized to full capacity. The province will likely be able to build an extra 2,875 MW of power from 2009 to 2025 [2]. This means that the production of electricity is assured in the future. The system is managed by a public provincial monopoly, which has as its main goal to economically and efficiently serve Manitoba load. Surplus electricity are sold to other provinces or the US in order to generate revenues which are used to lower electricity prices for Manitoba domestic customers. The direct consequence is that Manitobans pay the lowest price of electricity in Canada.

Even though adding other renewable energies in the distribution network can allow for more energy from hydro power to be exported, and reduce losses, these savings do not compensate for the higher cost of other renewables. Although the reliability of the system could increase by adding other renewables as local sources of supply.

\section{B. The rise of wind energy}

The second energy technology with increasing presence in the electrical system of Manitoba is wind power. There are currently 242 MW of wind power installed in Manitoba. This amount is small compared to the resources of wind that the province possesses. The Province has a desire to install 1,000 MW of this technology over the next several years. Its mass deployment is conditional on finding justifications other than the production of renewable energy, because this segment is covered by hydro power. One small scale justification is that wind energy can supply electricity to isolated diesel communities where the connection with the transmission system is not viable economically.

The installation of small wind generators has other challenges than economics, such as noise pollution, because they have to be installed near or on the roof of buildings. Moreover, small wind mills are not mass produced. These are opportunities for companies and research institutions to invent new lower costs products and create new business. Technologies such as the vertical axial wind turbine may have the possibility to fill this niche [3].

\section{Solar energy: an untapped source}

Studies show that Manitoba has better opportunity to

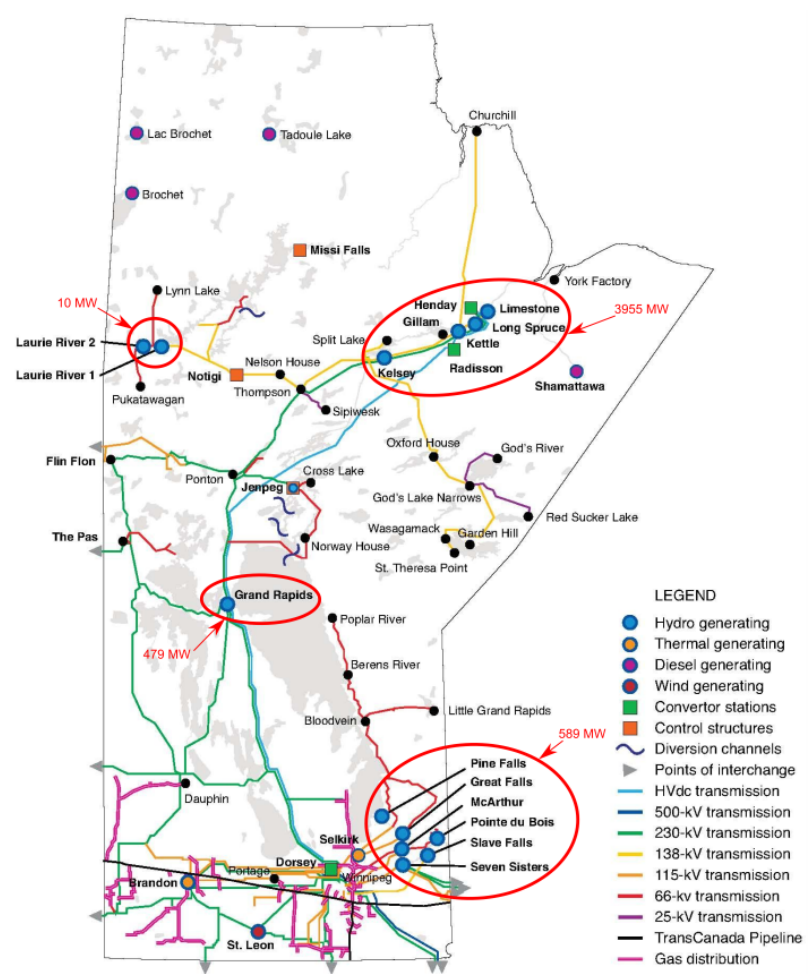

Fig. 1. Power systems of Manitoba. Retrieved from Manitoba Hydro-Electric Board 59th Annual report for the year ended March 31, 2010

exploit solar energy than other places due to climate and weather conditions: there are few cloudy days per year and average low temperatures most of the year [4] which improve the performance of the photovoltaic panels. It is estimated that if Manitoba used 1\% of the energy it receives from the sun, it could produce 200 times the actual demand of electricity (Figure 2). An argument against this is that the cost of the photovoltaic energy is about 40 cents per $\mathrm{kWh}$, in Manitoba while the current residential price of electricity is about 6 cents per kWh. In addition, the average electrical energy consumption of a Manitoban home is between $30-40 \mathrm{kWh} /$ day, and an installation of solar panels of $2 \mathrm{~kW}$ produces less than 10 $\mathrm{kWh} /$ day. This means photovoltaic energy is very expensive and may only cover only a small part of the electricity consumption of a family [5].

Although it might seem difficult to justify the installation of photovoltaic arrays, it is one of the few technologies in which a domestic user can easily install. The participation of home owner in the electric market as a producer has advantage which is the educational component: the users have more motivation to develop a culture of energy efficiency. Moreover some have stated that this technology can be used to offer services such as improving power quality or ancillary services, because it could use batteries and converters to connect to the network. There a market for these services, but it is unlikely that the solar delivered electricity used to offer these services can be competitive with the conventional sources. However if many people decide to invest in solar panels, the price of this technology could decrease quickly, because there are millions of potential buyers world wide. Hence, in the future solar energy has a huge potential to become an attractive economical option for 


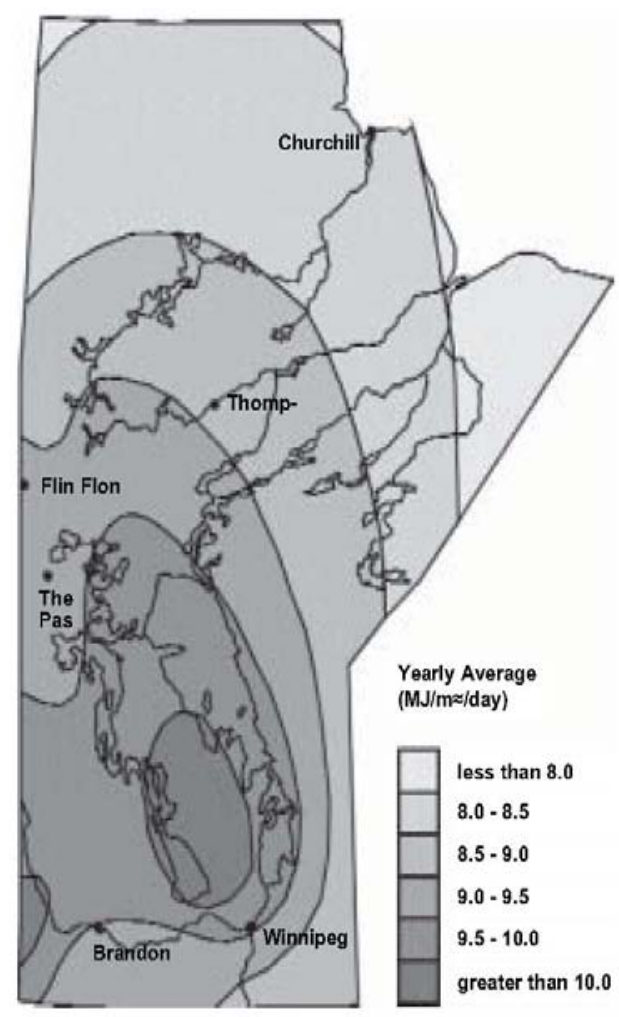

Fig. 2. Direct solar energy in the province of Manitoba

families, farmers and small companies that do not have the financial resources to install the large generators used by utilities. Solar costs have been decreasing rapidly for several years now and will continue to do so.

\section{Electric transport in Manitoba}

The emission from transportation causes a significant contribution to greenhouse gases around the world as well as pollution and the related health issues. Decreasing the emission impact of transportation is a challenge because the internal combustion engine has a long history; internal combustion engines are reliable, and are a source of revenue for many sectors of the economy. Applying electric technology to cars is not new but the difficulties with storage and other factors have delayed its deployment until recently.

\section{A. The use of cars in the province.}

Greenhouse gases from vehicles in Manitoba are more relevant in percentage than in other provinces because most of the electric energy produced here is low emitting renewable hydropower. Based on data from Statistics of Transport Canada, the consumption of fossil fuels in transportation is more than one third of the total energy consumed in the province. There are more than 600,000 light duty vehicles in Manitoba (not considering trucks or other heavy vehicles). Each car travels an average of $18,500 \mathrm{~km} /$ year, and the average fuel consumption is 10.5 litres $/ 100 \mathrm{~km}$. That means Manitobans would have a large opportunity to reduce the consumption of gasoline if they adopted the plug-in electric vehicle as a model of mobility. In addition, all the cities in the province have parking lots with engine block heater outlets. There are more than 500,000 of them in the city of Winnipeg alone [6]. The block heater outlets can be used to recharge batteries of electric vehicles with less investment than in most cities of the world. Taking into account that the electric energy in Manitoba is the cheapest in Canada, the conclusion is that Manitoba and its cities have an advantageous position to gain the most savings by introducing plug-in electric vehicle on a mass scale.

\section{B. First experiences of electric vehicles in Manitoba.}

There are several projects in Manitoba which try to identify the pros and cons of using the plug-in electric vehicle and its components. One of them is the battery repurposing project being researched by Manitoba Hydro. The idea is to investigate if low cost utility scale battery storage is possible by re-using the EV battery for grid energy storage after the battery storage capacity has depleted to $80 \%$ of its initial value and is no longer viable in a car. This also facilitates the adoption of EVs because now the "spent EV battery" has a residual value. A second experiment was done in the summer of 2009 to test the capacity of the distribution network to charge eight plug-in electric vehicles simultaneously on the same feeder of a parking lot. This experiment was focused on harmonics, and the results were that the influence of vehicles is low [6]. The most interesting aspect is the modification of the load demand curve during a day. The experiment was only able to identify an increment in the demand of about $30 \%$ to $40 \%$ during the time of recharging, which it is not enough to distinguish the variations in the load curve throughout the day, but which gives an approximation of the effect in the distribution network. More than 100 cars can be stationed in the parking lot studied. So the extrapolation of results shows the necessity of investment in the distribution network to avoid overloading of feeders and distribution transformers.

Another demonstration project was developed by the Province of Manitoba in 2008 [6]. The objectives were to gain knowledge in all aspects of this technology, and to identify the possible economic gains related to electric vehicles. Thus, it modified 10 hybrid electric vehicles to plug in to the distribution network, and monitored them during three years. The project has already yielded results, identifying problems and proposing solutions related to the specific weather conditions in the province such as unnecessary the start-up when the temperature is low to warm up the catalytic connector when in EV mode or the increment in electrical energy consumption to warm up the cabin of vehicle as well as charging the battery at the same time. It also studied the patterns of driving and how they affect the consumption of fuel. The electric plug-in vehicles saved an average of 6.2 litres $/ 100 \mathrm{~km}$ in the first period of study. This saving is significant when compared with the data mentioned in the section before, but it is overly dependent on the users and abilities of the drivers due to the non optimized nature of these converted vehicles. The next step would be to research if a pure electric vehicle would operate satisfactory in Manitoba. 


\section{Advantages and opportunities of this technology}

The goal of the consortium of a large group of companies involved in the deployment and development of electric vehicles (EV) in Canada is to reach half million capable plug-in electric vehicles in the country by 2018 [7]. If this prognosis is correct, there will be a huge investment in electric vehicles in Canada in the following years.

The main argument in favour of electric vehicles is that they are more efficient in the consumption of energy, and if the source of electricity comes from a clean renewable energy sources they do not contribute to greenhouse gases. As a consequence, the dependence on refined oil would be reduced and the prices of propulsion energy would be more stable. There are also other advantages such as better performance, because the electric engine recovers energy from braking, and gets the maximum torque at zero rpm [7].

Another positive aspect is the possible participation of vehicles in the electricity market by means of delivery of the energy storage in their batteries. This energy can be used to cover peaks in the demand of electricity, or flattening the load curve. However, this will only occur if the cost of the current batteries can be reduced by a factor of five. The social benefits of electric vehicles can be summarized in four points: new employment and entrepreneurship opportunities, saving money in fuel, reduction of pollution, and education in energy efficiency [8]. Manitoba is in a good position to get all the advantages of the deployment of electric vehicles, and as has been mentioned before, there are institutions in the province with background in the technology. However, it is necessary to ensure the distribution network is able to integrate these new loads by using smart grid technology at high levels of EV penetration by upgrading distribution transformers when the new EV exceed the transformer loading. Thus the automation of the distribution network and the participation of the renewable energies are the key to success in the deployment of electric vehicles at large scale.

\section{Future: Smart Grid}

Smart grid is a concept that defines a potential future electric distribution and transmission network. Basically, it could involve the use of distributed energy sources, storage with information technologies to improve the efficiency and performance of the grid. In order to attain these goals it is necessary to add monitoring, analysis, control and communication capabilities that will optimize the operation of the entire electrical grid.

\section{A. The distribution network and parking lots}

The large scale usage of electric vehicles could affect the distribution network in at least two ways. The first is the presence of electric mobile loads. An electric vehicle can be plugged into the network of private houses, in new recharging stations, or in public parking. The outcomes will be a change in the power demand profile (time and location). Thus, the lifetime of lines and transformers could be reduced because there will be an increases in the usage patterns, and they may need to be replaced sooner. The second effect is the deployment of new cables at a low voltage level to serve the electric vehicle charging load in parking lots. This is less problematic in Manitoba because a low voltage network (for parking lots) is already present, in contrast with the situation in most cities of the US and Europe.

\section{B. Power quality issues}

The integration of renewable energy sources in the distribution network presents several challenges in the field of the power quality such as harmonics, coordination of protection systems and imbalances of the three phase system. Harmonics are not a big problem because the electronic interfaces between the source and the network have been improved with new algorithms of commutation and filters that reduce the harmonics to levels which do not cause problems in other electric loads. Although there may be some doubts in the case of large penetration of distributed generation if their communication systems or the islanding signals can be affected by harmonics. More research is required on this issue. Short-circuit currents also appear in non faulted feeders and the values of them are modified along the feeders. The existing protection relays in the distribution system may not be easily programmed for solving all the possible situations in which the renewable sources can change the short-circuit currents and may need to be upgraded. Otherwise there may be more voltage sags and interruptions in the loads. In other words, a decrement in the power quality. The imbalance of the three phase system is caused by the connection of the single-phase loads or sources in the network. Most of the converters of current electric vehicles chargers and small renewable energies less than $100 \mathrm{~kW}$ are of this type. The imbalance of voltage produces malfunction in some loads, and the imbalance of currents introduces current in the neutral wire. If not properly balanced, the flow of current in the neutral wire can be considered a fault by some protection devices, and could cause false trips. Dynamic load balancing may be required in the future.

\section{Smart grid; automation of the distribution network}

The current distribution network is likely not designed to support changes such as the large scale introduction of the electric vehicles, the connection of distributed energy sources, and the power quality problems which these devices may introduce in the network. The answers to many of these new challenges is the Smart Grid. The main idea in the Smart Grid concept is the automation of the distribution network. The concept is used to find solutions for making the advantages of the distribution generation and electric vehicles a reality. The automation of the distribution network has three direct implications. The first is the implementation of the necessary algorithms of control to manage the demand, and avoid instabilities. The second is the exchange of information between the facility and the consumers to optimize the use of the energy from the technical and economic points 
of view. The third is the improvement of the flexibility and reliability of the network. Better communication and information can allow fast network reconfiguration after contingencies which will lessen the risk of blackout. Therefore the benefits are for both the consumer and the distribution company.

\section{Conclusion}

Most of the countries in the world are trying to reduce energy dependence on fossil fuels, and avoid the emission of greenhouse gases to the atmosphere. For these objectives, governments are investing huge quantities of money in the deployment of renewable energies and modification of electric power systems to accommodate them. The benefits of doing that are also clear in Canada, but there are some provinces where there are no reasons to add these new renewables because they already use a renewable energy (hydro power) as a main source of electricity, and these other renewable energy sources like wind and solar are expensive when compared with hydropower. This is the case of Manitoba.

The production of electricity in Manitoba is abundant, clean and cheap, with up to $1 / 3$ of electricity being sold to the US and other provinces. There are plenty of untapped natural sources of energy such as wind and sun, and hydro power is produced far away from the main cities of the province which implies losses in the transmission of the electricity. However, today the value of the reduced losses and the potential profits from the increased opportunity to export more energy will not cover the higher electricity costs from wind and solar. So a triple bottom line approach needs to be used to justify if wind and solar make sense in Manitoba along with abundant hydro power. Triple bottom line means encompassing economic, social, and environmental benefits into the evaluation of new energy sources. Lastly a smart grid will be necessary to integrate a large penetration of EVs and will also assist in integrating distributed generation like solar and wind. Moreover, Manitoba has a large energy expenditure in fossil fuels caused by transportation. There are, however, new alternatives such electric vehicles to reduce the consumption of refined oil.

\section{References}

[1] C. J. Ferguson-Martin and S. D. Hill, "Accounting for variation in wind deployment between Canadian provinces." Energy Policy, vol. 39, pp. 1647-1658, 2011.

[2] R. J. Goodman, Power connections: Canadian electricity trade and foreign policy. Canadian International Council. Toronto, ON:, 2010.

[3] M. Islam, A. Fartaj, and T. D.S.K., "Current utilization and future prospects of emerging renewable energy applications in Canada.” Renewable and Sustainable Energy Reviews, vol. 8, pp. 493-519, 2004.

[4] H. Cutforth and D. Judiesch, "Long-term changes to incoming solar energy on the Canadian Prairie.” Agricultural and Forest Meteorology, no. 145, pp. 167-175, 2007.

[5] "Government of Manitoba. Innovation, Energy and Mines Department. Photovoltaic systems in Manitoba,” March 14 2011. [Online]. Available: http://www.manitoba.ca/iem/energy/ initiatives/pdf/photovoltaic.pdf

[6] "Government of Manitoba. Innovation, Energy and Mines Department. Plug-in hybrid electric vehicle demonstration: Manitoba PHEV demonstration. Report of first year operations 2008/2009.” March 14 2011. [Online]. Available: http://www. manitoba.ca/iem/energy/transportation/images/phev_first_repor t_hi.pdf

[7] E. M. Canada, Electric vehicle technology roadmap for Canada: A strategic vision for highway-capable battery-electric, plug-in and other hybrid-electric vehicles. Government of Canada. Ottawa, ON:, 2010.

[8] T. Molinski and E. Innes, "Effectiveness of utilizing renewable energy for PHEVs," in Effectiveness of utilizing renewable energy for PHEVs, June 202005. 